\title{
Determining Balıkesir's Energy Potential Using a Regression Analysis Computer Program
}

\author{
Bedri Yüksel and Ergun Ateş \\ Faculty of Engineering and Architecture, The University of Balıkesir, Department of Mechanical Engineering, Balıkesir, Turkey \\ Correspondence should be addressed to Ergun Ateş; ergunates@gmail.com
}

Received 22 September 2013; Accepted 13 January 2014; Published 25 February 2014

Academic Editor: Jing Shi

Copyright (C) 2014 B. Yüksel and E. Ateş. This is an open access article distributed under the Creative Commons Attribution License, which permits unrestricted use, distribution, and reproduction in any medium, provided the original work is properly cited.

\begin{abstract}
Solar power and wind energy are used concurrently during specific periods, while at other times only the more efficient is used, and hybrid systems make this possible. When establishing a hybrid system, the extent to which these two energy sources support each other needs to be taken into account. This paper is a study of the effects of wind speed, insolation levels, and the meteorological parameters of temperature and humidity on the energy potential in Balıkesir, in the Marmara region of Turkey. The relationship between the parameters was studied using a multiple linear regression method. Using a designed-for-purpose computer program, two different regression equations were derived, with wind speed being the dependent variable in the first and insolation levels in the second. The regression equations yielded accurate results. The computer program allowed for the rapid calculation of different acceptance rates. The results of the statistical analysis proved the reliability of the equations. An estimate of identified meteorological parameters and unknown parameters could be produced with a specified precision by using the regression analysis method. The regression equations also worked for the evaluation of energy potential.
\end{abstract}

\section{Introduction}

The growing global energy problem highlights the increasing need for new and renewable energy sources on a daily basis, with wind and solar energy being the most obvious. According to the Global Wind Energy Council the total wind energy capacity of Turkey was 1329 MW in 2010 [1]. The annual average wind speed in the Marmara region for heights of 30,50 , 70 , and 100 meters is $5.5-9.5 \mathrm{~m} / \mathrm{sec}$, as revealed in a study of Turkey's wind energy potential and energy profile [2]. The annual average wind speed and solar energy of the Marmara region are $3.29 \mathrm{~m} / \mathrm{sec}$ and $51.91 \mathrm{~W} / \mathrm{m}^{2}$, respectively, which is considerably higher than most of the other regions of Turkey [3]. Turkey has the potential to generate electricity from both wind and solar sources. Wind can be unpredictable throughout the year, season, or even during a single day and varies by geographical region [4]. According to the European Commission Photovoltaic Geographical Information System's analysis of Turkey, the yearly insolation per meter square is $2,040 \mathrm{kwh} / \mathrm{m}^{2}$, demonstrating the country's considerable solar potential [5]. Considering the unreliability of solar energy due to variances in insolation levels, recent research has stated that the reliability of the system can be increased through the use of two or more complementary alternative energy sources [6].

Studies into wind-solar hybrid systems have been based on the establishment of different systems, and analyses of their potential have been carried out to identify their efficiency. Systems that incorporate two or more renewable energy sources are called hybrid power systems, which may be used to resolve the variability issues related to renewable energy sources [7]. According to the forecast by Pernick et al. (2012), the market share of renewable energy will reach a total of $\$ 400$ billion in the next 10 years. For 2011, the values of power produced from wind energy and solar batteries, which are considered the most important renewable energy sources of the future, were $\$ 71.5$ billion and $\$ 91.6$ billion, respectively. Support for wind-solar industries and their complementary characteristics has led to the development of hybrid energy systems in which wind-solar and wind-micro hydroelectric generators are used together. The use of more than one renewable energy source in electricity production increases initial start-up costs, as well as making the structure and design of the system complex [8]. Although there is enough energy for 
the system to produce electricity from a solar-only source between April and November in the western and the southern regions of Turkey, a supplementary source is necessary for the winter months, which can be provided by wind energy in areas with adequate wind potential [9]. El-Shatter et al. carried out an analysis of the movements of the sun in order to gain maximum power from the hybrid system [10]. Rivera, using his established hybrid system, calculated the effect of system elements on electrical energy production, ascertaining that 25 percent of the energy produced was lost by the invertors, the regulator, the turbine, and the accumulators [11]. Although there are a number of statistical studies of meteorological data, they tend to be specific studies of particular regions in the countries, where the researchers were based. Ge and Xiang carried out a statistical analysis to calculate the average wind speed in Shanghai, China. In the study, data related to wind speed and direction were used (the greatest value was recorded every 2 hours) [12]. Anagreh et al. examined the distribution of the data using Skew-Normal (SN), Weibull, Chi-Square, and Kolmogorov-Smirnov (KS) statistical tests in order to evaluate the renewable energy potential with wind speed and solar radiation measurements. The data showed that Aqaba had significant potential to support hybrid renewable energy systems [13]. Sanchez et al. in their study reviewed numerous works that have developed different models with the objective of detecting hail precipitation using meteorological radar. For kinetic energy "methodology based on ingredients" has enabled us to explain the results derived from a meteorological perspective, while using exclusively statistical criteria when constructing the logistic prediction model. Once the necessary ingredients were identified, the stepwise method for the introduction of variables was used to construct a logistic prediction model for kinetic energy [14]. Ocampo and Rivas, in their study, highlight that knowledge of daily net radiation $(\mathrm{Rn})$ is a basic requirement for quantifying energy used in various processes occurring at the surface levels such as evapotranspiration. This study applies a multiple linear regression model (MRLM) for the estimation of Rn in a subhumid-humid zone of Argentina. In the model they used weather data of solar radiation, temperature, relative humidity, $\mathrm{Rn}$ (measured with a Kipp \& Zonen net radiometer), and inverse relative earthsun distances. As a result, eight estimation equations of $\mathrm{Rn}$ were derived. The results showed a good adjustment and a low error on a daily scale, highlighting those equations involving solar radiation, temperature, relative humidity, and inverse earth-sun distance, allowing calculation of Rn with errors less than $19 \mathrm{~W} / \mathrm{m}^{2}$ [15]. In the study by Almorox et al., for locations where measured values are not available, several models have been developed to estimate solar radiation. All models were based on easily available meteorological variables, without using hours of sunshine as input, and were used to estimate the daily solar radiation at Canada de Luque (Cordoba, Argentina). The results showed that all the analyzed models were robust and accurate $\left(R^{2}\right.$ values between 0.87 and 0.89 ), so global radiation can be estimated accurately with easily available meteorological variables when only temperature data is available. The daily global solar radiation values produced by these models can be used in hydrologic or agricultural applications to estimate missing daily values, when only temperature data is available [16].

The purpose of this study is to identify the wind and solar energy potential of the Balıkesir University Çağış region through the use of equations obtained from statistical studies and to make accurate forecasts. A computer program was developed for the rapid calculation of data. Wind speed, insolation levels, biannual temperatures, and humidity parameter values were used as data in the study. The wind speed and insolation levels were taken as the main parameters, while temperature and humidity were incorporated as secondary variables.

\section{Materials and Methods}

Monthly climatological data and daily meteorological tables supplied by the Ballkesir Meteorology Home Office were used in the study. Monthly averages from a 24-month period, from May 2010 to April 2012 (Table 1), were calculated [17]. The maximum 10-minute average wind speed $(W, \mathrm{~m} / \mathrm{s})$, total insolation level $\left(\mathrm{Q}, \mathrm{cal} / \mathrm{cm}^{2}\right)$, average temperature $\left(T,{ }^{\circ} \mathrm{C}\right)$, and average relative humidity $(H, \%)$ were used as meteorological data. Wind speed at 10-meter heights was calculated, along with the insolation level, temperature, and humidity at 2 meters. The precise location of the measurement was latitude $39^{\circ} 37^{\prime}$, longitude $27^{\circ} 55^{\prime}$.

Meteorological measurements were detailed and varied. Wind speed was taken as an average of data measured every minute. The insolation level was calculated as the average of the daily measured total insolation level. The average temperature and average relative humidity were taken as the average values for a single day.

In order to derive an equation to analyse regression, different mathematical methods can be used. The distribution of data can be the basis for the formation of the equation. At the beginning of the study, it can be decided which method to use. The margin of error of calculated data from the regression equation should be minimal. Previous literature has shown that the multiple linear regression is the preferred method for statistical calculation due to the accuracy of its results. For this reason, the multiple linear regression method was chosen to analyse the data in this study [18].

Using the multiple linear regression method, two equations were derived from the data in Table 1, in which the dependent variables were, respectively, wind speed and insolation levels, with the other three data sets being independent variables. In these equations, the meteorological data was defined as independent variables, and wind speed and insolation levels were calculated as dependent variables. Monthly average values of meteorological data were calculated using a regression equation. The differences between the observed and calculated regression equations were determined.

Table 2 shows the average values observed for the four months from May to August 2012 [17]. The data in Table 2 was not used to derive the regression equations, but rather to forecast meteorological parameters.

In statistical studies it is well known that analysis of large quantities of data is more significant than those made with 
TABLE 1: The monthly average meteorological parameters from May 2010 to April 2012.

\begin{tabular}{lccc}
\hline $\begin{array}{l}\text { Wind speed } \\
(W) \mathrm{m} / \mathrm{s}\end{array}$ & $\begin{array}{c}\text { Total insolation } \\
\text { level } \\
(\mathrm{Q}) \mathrm{cal} / \mathrm{cm}^{2}\end{array}$ & $\begin{array}{c}\text { Average } \\
\text { temperature } \\
(T){ }^{\circ} \mathrm{C}\end{array}$ & $\begin{array}{c}\text { Average relative } \\
\text { humidity } \\
(H) \%\end{array}$ \\
\hline 6.67 & 544.77 & 17.30 & 66.20 \\
7.80 & 577.08 & 22.10 & 61.40 \\
8.48 & 647.70 & 25.80 & 56.35 \\
9.38 & 589.70 & 25.80 & 55.95 \\
8.44 & 447.85 & 21.60 & 60.85 \\
6.97 & 267.70 & 13.75 & 73.30 \\
6.51 & 200.78 & 9.55 & 74.85 \\
5.67 & 121.68 & 6.90 & 81.20 \\
5.82 & 133.83 & 3.40 & 82.60 \\
6.46 & 216.92 & 3.60 & 78.80 \\
7.25 & 329.32 & 7.35 & 70.45 \\
7.54 & 403.19 & 12.25 & 70.50 \\
\hline
\end{tabular}

TABLE 2: The monthly average meteorological parameters from May, June, July, and August 2012.

\begin{tabular}{lccc}
\hline $\begin{array}{l}\text { Wind speed } \\
(W) \mathrm{m} / \mathrm{s}\end{array}$ & $\begin{array}{c}\text { Total insolation } \\
\text { level } \\
(Q) \mathrm{cal} / \mathrm{cm}^{2}\end{array}$ & $\begin{array}{c}\text { Average } \\
\text { temperature } \\
(T){ }^{\circ} \mathrm{C}\end{array}$ & $\begin{array}{c}\text { Average relative } \\
\text { humidity } \\
(H) \%\end{array}$ \\
\hline 6.64 & 501.72 & 17.4 & 74.1 \\
8.54 & 701.50 & 24.1 & 56.7 \\
9.64 & 670.07 & 27.1 & 52.9 \\
10.05 & 615.69 & 25.3 & 51.7 \\
\hline
\end{tabular}

simple operations; however, large data sets make finding a solution difficult and time consuming. The preparation of a computer program to analyze large amounts of data and matrix solutions brings flexibility to the process, as has been the case in this study. The flexibility in this case comes from the number of replaceable dependent and independent variables, and in addition, the amount of data can also be changed. To this end, in order to write the computer program to arrive at a solution, MS-Quick Basic version 4.5 was used as the compiler, as it is compatible with many operating systems, including MS-DOS and Windows 95, 98, ME, and XP [19].

In this study, code has been written to derive the regression equation. In addition, the standard deviation, the mean, the standard error, probability, and $R^{2}$ need to be calculated. Furthermore, regression equations of the wind speed and the total insolation were calculated by using statistics software. The regression equations derived using the statistical program (the subject of this study) were compared with the regression equations (the IBM SPSS statistics software v.19 [20]). In this way, evaluation of the regression equations from this study could be made more efficiently.

The SPSS software was used to carry out a linear regression analysis of the observation values from Table 1 , and wind and insolation regression equations were derived. The results are displayed in Table 3. In the first calculated regression equation (using SPSS software), wind $(W)$ is the dependent variable, and temperature $\left(T=x_{1}\right)$, humidity $\left(H=x_{2}\right)$, and insolation $\left(Q=x_{3}\right)$ are the independent variables ( $(\mathrm{i})$ in Table 3). In the second regression equation (using SPSS software), the insolation level $(Q)$ is the dependent variable, and wind $\left(W=x_{1}\right)$, temperature $\left(T=x_{2}\right)$, and humidity $(H=$ $x_{3}$ ) are the independent variables ((ii) in Table 3 ). In (i) the wind speed subindex is shown with WS. In (ii) the insolation level subindex is shown with QS.

In this study, the results from the SPSS software have been displayed with the results of the prepared regression equation in order to allow easy comparison of the two.

\section{Experimental Study}

The statistical method used was a multiple linear regression method, which aims to find the best equations to represent data using the smallest squares and a matrix approach (1). Consider

$$
\begin{gathered}
y_{i}=\beta_{0}+\beta_{1} x_{i 1}+\beta_{2} x_{i 2}+\cdots+\beta_{k} x_{i k}+\epsilon_{i}, \\
X^{\prime} y=\left(X^{\prime} X\right) \widehat{\beta}, \\
\widehat{y}_{i}=\widehat{\beta}_{0}+\sum_{j=1}^{k} \widehat{\beta}_{j} x_{i j}, \\
e_{i}=y_{i}-\widehat{y}_{i} .
\end{gathered}
$$

In (1), $y_{i}$ is the dependent variable, $\beta_{0}$ is the constant, $\beta_{k}$ is the constant of the independent variable, $x_{k}$ is the independent variable, $\epsilon_{i}$ is the error, $i$ is the arbitrary state, and $k$ is the arbitrary heap. Equation (2) is an expression of dependent and independent variables and their constants in a matrix form. In (2), $y$ is the matrix of the dependent variable, $X$ is the matrix of the independent variable, $X^{\prime}$ is the transposition of the independent variable matrix, and $\widehat{\beta}$ is the matrix form of the independent variable constants. Equation (3) shows the calculated regression equation after the matrix equations have been calculated according to the dependent and independent variables and constants, using all the data. In (3), $\hat{y}_{i}$ is the dependent variable of the calculated regression equation, $\widehat{\beta}_{0}$ is the constant of the regression equation, $\widehat{\beta}_{j}$ is the independent variable constant of the regression equation, $x_{i j}$ is the independent variable of the regression equation, and $j$ and $i$ are the state and heap arbitraries. Equation (3) is stated in a general form, and meteorological data is captured in the observation regression equation, and the dependent variable is calculated. This new value is a dependent variable that is calculated according to the regression equation, and so differences with the observed values may occur, although the ideal difference is zero, or at least an insignificant value. Mathematical differences between the meteorological observation data and the data from the regression equation were calculated using (4). In (4), $y_{i}$ is the dependent variable observation value, $\hat{y}_{i}$ is the calculated value of the dependent variable regression equation, and $e_{i}$ is the difference between the two.

The objective is to write software to calculate the regression equation. The algorithm of the software showing the 
TABLE 3: Descriptive statistics, $R^{2}$, and regression equations from SPSS software.

\begin{tabular}{|c|c|c|c|c|}
\hline Model & $W$ & $Q$ & $T$ & $H$ \\
\hline Mean & 7.2492 & 373.3800 & 14.1083 & 69.3500 \\
\hline Std. dev. & 1.12736 & 187.68096 & 8.26209 & 9.29540 \\
\hline$R^{2}=0.915$ & \multicolumn{4}{|c|}{ (i) $y_{W S}=(25.178)-(0.047) x_{1}-(0.228) x_{2}-(0.004) x_{3}$} \\
\hline$R^{2}=0.937$ & \multicolumn{4}{|c|}{ (ii) $y_{Q S}=(3207.004)-(79.918) x_{1}-(4.012) x_{2}-(31.690) x_{3}$} \\
\hline
\end{tabular}

operations necessary for determining the regression equation is shown in Figure 1.

The SPSS program contains an explanatory menu which describes the operations that are possible. The $y_{i}$ dependent and $x_{i}$ independent variable values and the observation data values are entered. The sum of the dependent and independent variables $\sum x_{i}, \sum y_{i}$ and the arithmetic averages of $\bar{x}_{i}$, $\bar{y}_{i}$ are calculated from the observed data values. The sum and arithmetic average values (in matrix form) of the dependent and independent variables are calculated to derive the dependent $y$ and independent $X$ variable matrix.

Transposition of the independent variable $X$ matrix results with the transposition $X^{\prime}$ matrix is then carried out. By applying this data to (2), the constants of $\widehat{\beta}_{1}, \widehat{\beta}_{2}, \ldots, \widehat{\beta}_{k}$, the independent variables, are calculated. By using the constants and arithmetic averages of the calculated independent variables, the $\widehat{\beta}_{0}$ constant number is calculated. Entering all the values into (3) allows the regression equation to be obtained, which defines the most suitable curve, representing all of the data of the dependent and independent variables. By applying the independent variable observation values to the regression equation, a new dependent variable is obtained for each data set. This value is the result of the regression equation, and the difference between the observation dependent variables $e_{i}$ is found by using (4). In this way the analysis is completed.

To test the result, three sample data sets that were manually prepared were used. Having tested the equations, the output can be transferred to an Excel file, which allows easy manipulation by an MS-DOS or XP operating system. The standard deviation, mean, mean standard of error, probability, and limits of the monthly data in the regression equations are calculated to evaluate the usability of regression equations. By inserting the wind speed and insolation levels into the regression equations in the observation data fields in Table 2, regression data related to wind speed and insolation levels can be obtained and compared to the observation data.

\section{Results and Discussion}

4.1. The Prepared Regression Software Solution. Continuity of wind speed and insolation levels lead to a high energy potential, and it is accepted that temperature and humidity have an indirect effect on these two parameters. Generally, a high temperature equates to a high level of solar energy, whereas when wind speed is high, humidity is low. In this paper, in which the aim is to identify the energy generation potential of the wind speed and insolation levels found in Balıkesir, these two parameters are rudimentary. In the first calculated regression equation, wind speed $(W)$ is the dependent variable, and

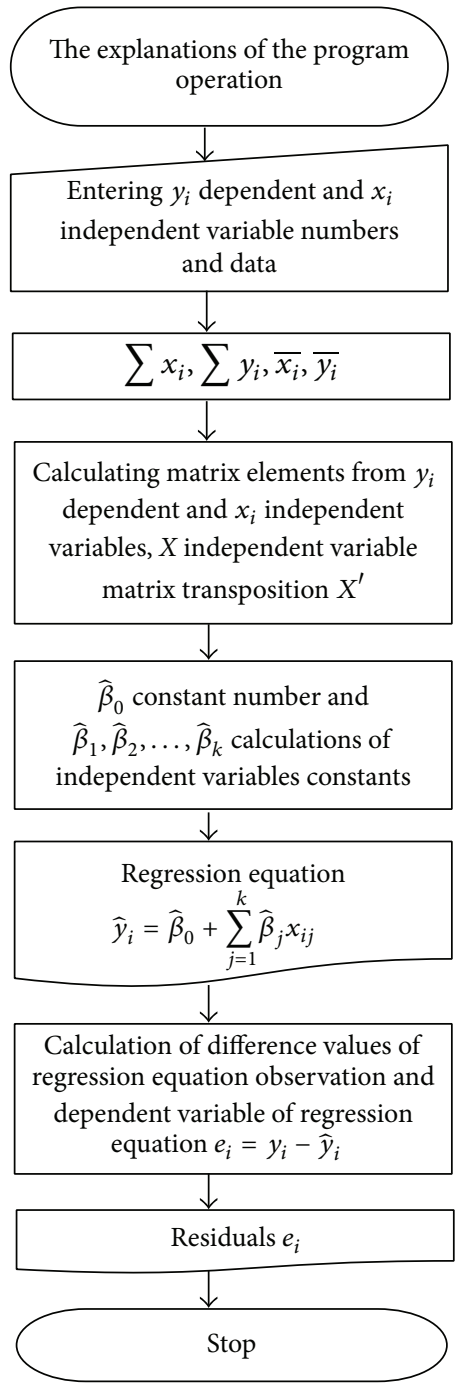

FIgURE 1: The designed algorithm for the regression equation.

temperature $\left(T=x_{1}\right)$, humidity $\left(H=x_{2}\right)$, and insolation levels $\left(Q=x_{3}\right)$ are the independent variables (5). In the second regression equation, the insolation level $(Q)$ is the dependent variable, and wind speed $\left(W=x_{1}\right)$, temperature $(T=$ $\left.x_{2}\right)$, and humidity $\left(H=x_{3}\right)$ are the independent variables (6). In (6) the insolation level subindex is $Q$. In (5) the wind speed subindex is shown with $W$. Consider

$$
\begin{aligned}
y_{W}= & (25.373542786)-(0.047754142) x_{1} \\
& -(0.230230287) x_{2}-(0.003961098) x_{3},
\end{aligned}
$$




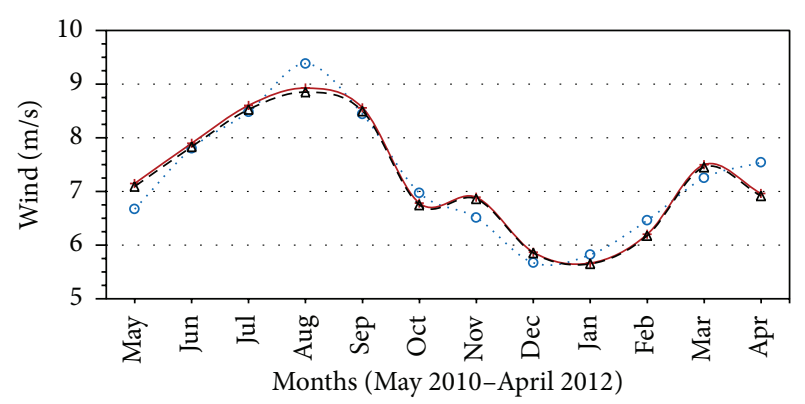

Wind-months

○. Observed

+ Fitted_cal

$-\Delta-$ Fitted_SPSS

FIgURE 2: The monthly change of wind speed.

$$
\begin{aligned}
y_{Q}= & (3228.488769531)-(80.144126892) x_{1} \\
& -(4.196159840) x_{2}-(31.928380966) x_{3} .
\end{aligned}
$$

The changes in wind speed and insolation levels in the months that were calculated using data obtained from the regression equations ((5) and (6)) are shown in Figures 2 and 3, respectively. The months are listed horizontally from 1 to 12 , with May being the first month. The data for each month is a two-year average. The vertical axis represents wind speed $(\mathrm{m} / \mathrm{s})$ in Figure 2 and insolation levels $\left(\mathrm{cal} / \mathrm{cm}^{2}\right)$ in Figure 3. As can be seen from Figure 2, wind observation and regression values follow a similar trend. The highest wind speed average was in August $(9.38 \mathrm{~m} / \mathrm{s})$, and the lowest was in December $(5.67 \mathrm{~m} / \mathrm{s})$. The highest and the lowest wind speeds are good proxies for wind potential. By using this data, the wind turbine can be used at the highest efficiency throughout the year.

As can be seen from Figure 3, the insolation level observation and regression values are similar. The highest insolation level was in July $\left(647.70 \mathrm{cal} / \mathrm{cm}^{2}\right)$, and the lowest was in December $\left(121.68 \mathrm{cal} / \mathrm{cm}^{2}\right)$. In the five months from May to September, an insolation level of $500 \mathrm{cal} / \mathrm{cm}^{2}$ or more is a significant value. The insolation level values obtained in this study are compatible with the values of the data observed in Balıkesir over the last thirty years [21].

In Table 4, the wind speed dependent variable observation $\left(y_{i W}\right)$ values and the regression equation results $\left(y_{W}\right)$ and their differences $\left(e_{i W C}\right)$ are shown. The $e_{i W C}$ values represent the level of difference from the observation values. An examination of the $e_{i W C}$ values reveals that the difference between the highest and the lowest ranges is from -0.478263931 to 0.579755821 . When the observation data and calculated differences are compared, it can be seen that the level of difference is low (at a decimal level). Thus, it can be concluded that the wind regression equations can be used with independent variable parameters.

The standard deviation $(\sigma)$ 1.078600886, mean $(\mu)$ 7.249164621, standard error of mean 0.311365256 , and limits $-2 \sigma<\mu<2 \sigma$ of the data that was calculated using the wind speed regression equation (5) are shown in Table 5. Obtaining

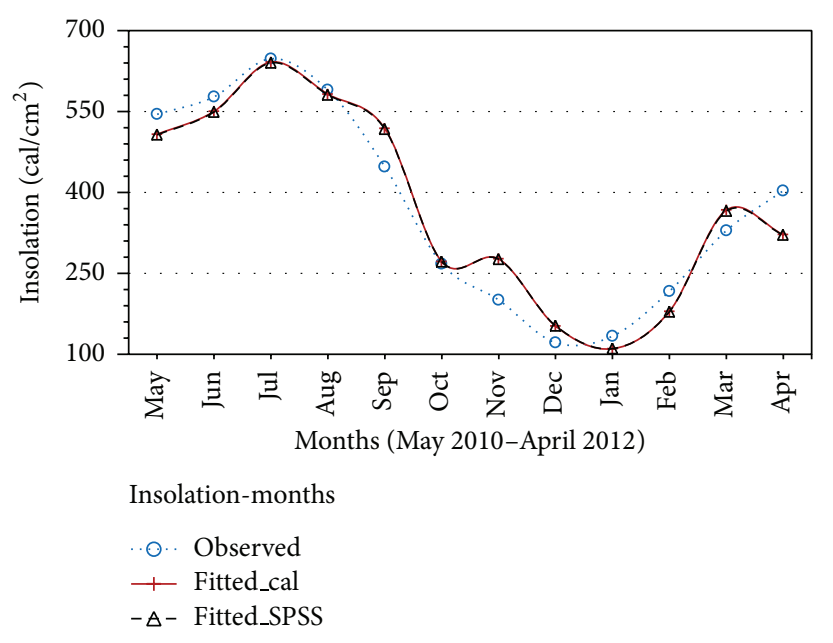

FIgURE 3: The monthly change of insolation level.

a standard error of mean that is smaller than the standard deviation demonstrates that the calculated wind regression equation can be employed to evaluate energy potential. The wind speed observations and calculated values are very close to each other. At $95.43 \%$, the probability displayed in Table 5 shows that the data distribution is reliable, and the calculated limits $-2 \sigma<\mu<2 \sigma$ are acceptable in engineering applications.

The insolation level dependent variable observation $\left(y_{i \mathrm{Q}}\right)$ values and the regression equation $\left(y_{Q}\right)$ results and their differences $\left(e_{I Q C}\right)$ are shown in Table 6 . An examination of the $e_{I Q C}$ values reveals that the smallest and largest differences range between -76.057890625 and 81.341855469. A comparison of the observation values and the calculated differences shows that the insolation level regression equations can be used with independent variable parameters.

According to the insolation level regression equation (6), the standard deviation of the calculated data $(\sigma)$ is 181.791332535, the mean is $(\mu) 373.376475016$, the standard error of mean is 52.478637387 , and the limit is $-2 \sigma<\mu<2 \sigma$ (Table 7). The standard error of the mean is smaller than the standard deviation. Therefore the regression equation of the insolation levels can be used to determine energy potential. Using the current values, it can be seen that by taking values close to the insolation level in the calculation of the insolation level regression equation. The probability shown in Table 7 indicates that the data distribution is reliable, since the probability is 95.43 percent and the calculated limits of $-2 \sigma<\mu<$ $2 \sigma$ are acceptable in engineering applications.

For future estimates of regression equations of wind speed and insolation levels, the data is inserted into Table 2 in place of the observed data, and a comparison of the respective months is made (Table 8). A comparison of four months of wind and insolation levels reveals that the levels in one month were higher (May 2012) than the standard deviation, but lower in the other three (June, July, and August 2012). These results were important. The insolation levels and the wind speeds were successful for predicting future energy potential. The data in Table 2 was not used in the calculation of the 
TABLE 4: Observation values, results, and difference of regression equation when there is a dependent variable wind speed.

\begin{tabular}{|c|c|c|c|c|}
\hline $\begin{array}{l}\text { Observed values } \\
\left(y_{i W}\right)\end{array}$ & $\begin{array}{l}\text { Fitted-cal values } \\
\left(y_{W}\right)\end{array}$ & $\begin{array}{c}\text { Wind residuals } \\
\left(e_{I W C}=y_{I W}-y_{W}\right)\end{array}$ & $\begin{array}{l}\text { Fitted-SPSS values } \\
\left(y_{W S}\right)\end{array}$ & $\begin{array}{c}\text { Fitted-SPSS residuals } \\
\left(e_{I W S}=y_{I W}-y_{\mathrm{WS}}\right)\end{array}$ \\
\hline 6.67 & 7.148263931 & -0.478263931 & 7.09222 & -0.42222 \\
\hline 7.80 & 7.896165848 & -0.096165848 & 7.83178 & -0.03178 \\
\hline 8.48 & 8.602405548 & -0.122405548 & 8.52680 & -0.04680 \\
\hline 9.38 & 8.924240112 & 0.455759888 & 8.85000 & 0.53000 \\
\hline 8.44 & 8.558561325 & -0.118561325 & 8.49760 & -0.05760 \\
\hline 6.97 & 6.780655384 & 0.189344616 & 6.74855 & 0.22145 \\
\hline 6.51 & 6.889444351 & -0.379444351 & 6.86023 & -0.35023 \\
\hline 5.67 & 5.867353916 & -0.197353916 & 5.85338 & -0.18338 \\
\hline 5.82 & 5.664042950 & 0.155957050 & 5.65008 & 0.16992 \\
\hline 6.46 & 6.200239182 & 0.259760818 & 6.17472 & 0.28528 \\
\hline 7.25 & 7.498358727 & -0.248358727 & 7.45267 & -0.20267 \\
\hline 7.54 & 6.960244179 & 0.579755821 & 6.91549 & 0.62451 \\
\hline
\end{tabular}

TABLE 5: The standard deviation, mean, standard error of mean, probability, and limits of regression equation results for a dependent variable wind speed.

\begin{tabular}{|c|c|c|c|}
\hline \multicolumn{2}{|l|}{ Wind fitted-cal } & \multicolumn{2}{|l|}{ Wind fitted-SPSS } \\
\hline Standard deviation $(\sigma)$ & 1.078600886 & Standard deviation $(\sigma)$ & 1.05779 \\
\hline Mean $(\mu)$ & 7.249164621 & Mean $(\mu)$ & 7.20446 \\
\hline Standard error of mean & 0.311365256 & Standard error of mean & 0.38551 \\
\hline \multicolumn{2}{|c|}{ Probability: $95.43 \%$, limits: $-2 \sigma<\mu<2 \sigma$} & \multicolumn{2}{|c|}{ Probability: $95.43 \%$, limits: $-2 \sigma<\mu<2 \sigma$} \\
\hline
\end{tabular}

TABLE 6: The results and differences of the regression equation with isolation level as the dependent variable.

\begin{tabular}{lcccc}
\hline $\begin{array}{l}\text { Observed values } \\
\left(y_{i Q}\right)\end{array}$ & $\begin{array}{c}\text { Fitted-cal values } \\
\left(y_{Q}\right)\end{array}$ & $\begin{array}{c}\text { Insolation residuals } \\
\left(e_{i Q C}=y_{i Q}-y_{Q}\right)\end{array}$ & $\begin{array}{c}\text { Fitted-SPSS values } \\
\left(y_{Q S}\right)\end{array}$ & $\begin{array}{c}\text { Fitted-SPSS residuals } \\
\left(e_{i Q S}=y_{i Q}-y_{Q S}\right)\end{array}$ \\
\hline 544.77 & 507.675292969 & 37.094707031 & 506.66534 & 38.10466 \\
577.08 & 550.226806641 & 26.853193359 & 549.21240 & 27.86760 \\
647.70 & 641.441528320 & 6.258471680 & 640.05826 & 7.64174 \\
589.70 & 582.082885742 & 7.617114258 & 580.80806 & 8.89194 \\
447.85 & 518.593383789 & -70.743383789 & 517.50038 & -69.65038 \\
267.70 & 271.836669922 & -4.136669922 & 271.93354 & -4.23354 \\
200.78 & 276.837890625 & -76.057890625 & 276.42672 & -75.64672 \\
121.68 & 152.533447266 & -30.853447266 & 152.95814 & -31.27814 \\
133.83 & 110.498779297 & 23.331220703 & 110.64644 & 23.18356 \\
216.92 & 179.695068359 & 37.224931641 & 179.11852 & 37.80148 \\
329.32 & 367.247802734 & -37.927802734 & 365.54980 & -36.22980 \\
403.19 & 321.848144531 & 81.341855469 & 321.13028 & 82.05972 \\
\hline
\end{tabular}

TABLE 7: The standard deviation, mean, standard error of mean, probability, and limits of regression equation results with the isolation level as the dependent variable.

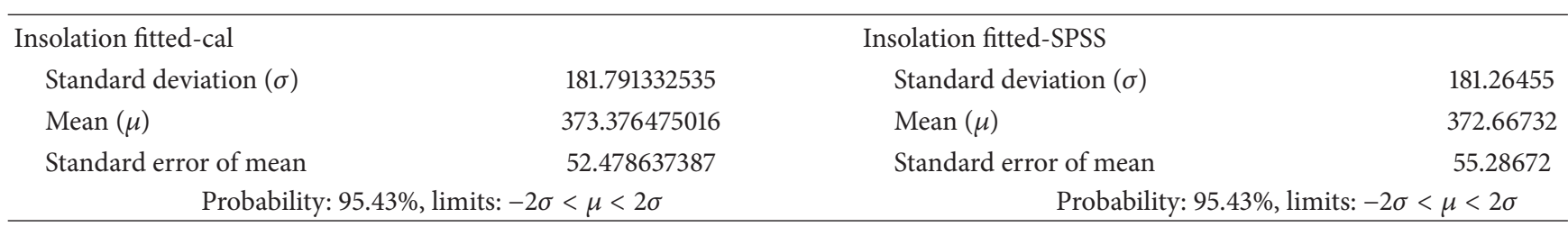


TABLE 8: The future estimation results obtained using the dependent variables, regression equations of wind speed, and insolation level data.

\begin{tabular}{|c|c|c|c|c|c|c|}
\hline Equation number & $\begin{array}{c}\text { Observed values } \\
y_{I W} \text { and } y_{i Q}\end{array}$ & $\begin{array}{c}\text { Fitted-cal values } \\
y_{W} \text { and } y_{\mathrm{Q}}\end{array}$ & $\begin{array}{c}\text { Fitted-cal } \\
\text { residuals } e_{I W C} \text { and } \\
e_{I Q C}\end{array}$ & Equation number & $\begin{array}{c}\text { Fitted-SPSS values } \\
y_{W S} \text { and } y_{Q S}\end{array}$ & $\begin{array}{c}\text { Fitted-SPSS } \\
\text { residuals } e_{I W S} \text { and } \\
e_{I Q S}\end{array}$ \\
\hline \multirow{4}{*}{$(3), y_{W}$ wind } & 6.64 & 5.496194354 & 1.143805646 & \multirow{4}{*}{$(5), y_{W S}$ wind } & 5.45852 & 1.18148 \\
\hline & 8.54 & 8.389900438 & 0.150099562 & & 8.31170 & 0.22830 \\
\hline & 9.64 & 9.246010413 & 0.393989587 & & 9.16282 & 0.47718 \\
\hline & 10.05 & 9.823648722 & 0.226351278 & & 9.73854 & 0.31146 \\
\hline \multirow{4}{*}{ (4), $y_{\mathrm{Q}}$ insolation } & 501.72 & 257.425556100 & 244.294443900 & \multirow{4}{*}{ (6), $y_{Q S}$ insolation } & 258.31068 & 243.40932 \\
\hline & 701.50 & 632.591272800 & 68.908727200 & & 630.99208 & 70.50792 \\
\hline & 670.07 & 653.172101300 & 16.897898700 & & 651.46828 & 18.60172 \\
\hline & 615.69 & 666.180154200 & -50.490154200 & & 663.95150 & -48.26150 \\
\hline
\end{tabular}

regression equation. The data from May which has a deviation from observed data reveals acceptable average values in insolation levels and wind speed, whereas the temperature and humidity are both low. Unexpected observation data at certain times of the year is important, in that it may result in a difference in the standard deviation.

4.2. The SPSS Software Solution. The prepared software and SPSS software results show a high level of compatibility. In Figures 2 and 3, the regression curves have very similar slopes for both wind speed and insolation level. In addition, the SPSS-calculated $R^{2}$ values for wind and insolation are 0.915 and 0.937 , respectively. The $R^{2}$ values obtained were very close to 1 which shows that the software developed can be used to predict meteorological data.

In this study, the main objective is to derive the regression equation; other required statistical parameters had not been added to the program. As part of a future study, these statistical parameters could be created. In addition an objectoriented interface could be developed.

The meteorological parameters can be used to design a hybrid system. The wind and insolation parameters were very important for this type of energy potential project. The parameters of wind speed and insolation level were priority parameters for regression equations.

It has been found that it is possible to predict the energy capacity of a given geographical region by using the regression equations derived in this study in conjunction with commercial software such as SPSS.

\section{Conclusion}

The compatibility of the method of analysis is important for any examined system, and the method that represents the system must be selected. Moreover, as unexpected natural events may occur, a complete evaluation cannot be made without taking these factors into consideration.

In this study, the wind and insolation level observation curves over a period of 24 months were as expected; and a close relationship was identified between the regression equation curves of the wind speed and insolation levels obtained via the multiple correlation method. In particular, the wind regression equation shows a close correlation with the ideal.

Although the dependent variable is wind speed $\left(\widehat{y}_{W}\right)$, when the difference between the results $\left(e_{i}\right)$ of the observation $\left(y_{i}\right)$ values and the regression equation $\left(\hat{y}_{i}\right)$ are compared, very small, almost indiscernible, differences occur, which shows the applicability of the regression equation to the quantification of energy potential in future forecasts. The other indicator of the applicability of the wind regression equation is the comparison of the standard deviation and the standard error of mean. The standard error of mean is calculated from the standard deviation for the equation. The limits of the wind regression equation data are in the range $-2 \sigma<\mu<2 \sigma$ and the probability is $95.43 \%$.

The insolation level regression equation can be used for energy potential evaluations or future forecasts. The standard error of mean is lower than the standard deviation. The insolation level regression equation can be used to predict energy levels with known differences. The limits of the insolation level equation data are in the range $-2 \sigma<\mu<2 \sigma$ and the probability is $95.43 \%$.

The mathematical operations followed in the multiple correlation methods adopted in this study require many matrix operations, where there is an increase in the parameters or independent variables. In these cases, manual calculation would be time consuming, and the recalculation of each operation would take a great deal of effort. For this reason, the use of a flexible algorithm program that can solve these problems quickly is important. When the results of the statistical evaluation of the wind speed and insolation level regression equations are taken into account, the software that has been developed can be used in other studies to calculate the insolation levels and the wind speed.

Furthermore, in this study, the results from the developed software overlap almost completely with the results from the SPSS program taken as a reference, further strengthening the case for using the developed software to predict wind speed and isolation levels.

The regression equations can also be used for future forecasts (except for unexpected seasonal meteorological events) with little margin of error. 


\section{Conflict of Interests}

The authors declare that there is no conflict of interests regarding the publication of this paper.

\section{References}

[1] GWEC, "European Wind Energy Council," 80 Rue d'Arlon, Brussels, Belgium, 2012, http://www.gwec.net/index.php?id= $133 \& \mathrm{~L}=0 \& 0$.

[2] Y. Malkoç, “Turkey wind energy potential and its place in our energy profile," EIE General Management, Turkey Wind Energy Communion, Green Office, Ankara, Turkey, (Turkish).

[3] C. İlkılıç, H. Aydın, and R. Behçet, "The current status of wind energy in Turkey and in the world," Energy Policy, vol. 39, pp. 961-967, 2011 (Turkish).

[4] M. Patel, Wind and Solar Power Systems, Taylor \& Francis Group, 2nd edition, 2006

[5] JRC, Photovoltaic Geographical Information System, European Commission, 2012, http://re.jrc.ec.europa.eu/pvgis/.

[6] M. Çolak, A. Özdamar, and M. Engin, "Ege University The Inner and Outer Lighting of Solar Energy Institution Building from Wind and Solar Energy," E. U. Research Fund Project Number 98/BİL/004, İzmir, Turkey, 2002, (Turkish).

[7] N. S. Çetin, "Fallowing up Qualified Work Power and Performance in Photovoltaic-Wind Hybrid Power System," Tech. Rep., Ege University Solar Energy Institution, Department of Energy Technology, Wind and Renewable Hybrid Energy System Groups, İzmir, Turkey, 2010, (Turkish).

[8] R. Pernick, W. Clint, and T. Winnie, Clean Energy Trends 2012, Clean Edge, 2012, http://www.cleanedge.com/reports.

[9] M. Engin and M. Colak, "PV-Wind hybrid energy system for lighting," in Proceedings of the Solar World Congress, International Solar Energy Society, Adelaide, Australia, November 2001.

[10] T. F. El-Shatter, M. N. Eskander, and M. T. El-Hagry, "Energy flow and management of a hybrid wind/PV/fuel cell generation system," Energy Conversion and Management, vol. 47, no. 9-10, pp. 1264-1280, 2006.

[11] M. R. Rivera, Small wind/photovoltaic hybrid renewable rnergy system optimization, a thesis submitted in partial fulfilment of the requirements for the degree of [Master of Science in Electrical Engineering], University of Puerto Rico, Mayagüez Campus, 2008.

[12] Y. Ge and H. Xiang, "Statistical study for mean wind velocity in Shanghai area," Journal of Wind Engineering and Industrial Aerodynamics, vol. 90, no. 12-15, pp. 1585-1599, 2002.

[13] Y. Anagreh, A. Bataineh, and M. Al-Odat, "Assessment of renewable energy potential, at Aqaba in Jordan," Renewable and Sustainable Energy Reviews, vol. 14, no. 4, pp. 1347-1351, 2010.

[14] J. L. Sanchez, L. Lopez, E. Garcia-Ortega, and B. Gill, "Nowcasting of kinetic energy of hail precipitation using radar," Atmospheric Research, vol. 123, pp. 48-60, 2013.

[15] D. Ocampo and R. Rivas, "Estimating daily net radiation from multiple linear regression models," Revista Chapingo Serie Ciecias Forestales Y Del Ambiente, vol. 19, no. 2, pp. 263-271, 2013.

[16] J. Almorox, M. Bocco, and E. Willington, "Estimation of daily global solar radiation from measured temperatures at Canada de Luque, Cordoba, Argentina," Renewable Energy, vol. 60, pp. 382-387, 2013.
[17] Metrologic Parameters, Balıkesir Field Meteorology Office, Balıkesir, Turkey, 2010-2012, (Turkish).

[18] D. C. Montgomery and G. C. Runger, Statistical, Applied Statistics and Probability for Engineers, John Wiley \& Sons, 3rd edition, 2003.

[19] MS-Quick Basic Version 4.5, Microsoft Corporation, 2012.

[20] IBM SPSS Statistics, Version 19, IBM Company, Licensed Software, The University of Warwick, UK, 2012.

[21] A. Kilıç and A. Öztürk, Solar Energy, Kipaş Distribution, İstanbul, Turkey, 1983, (Turkish). 


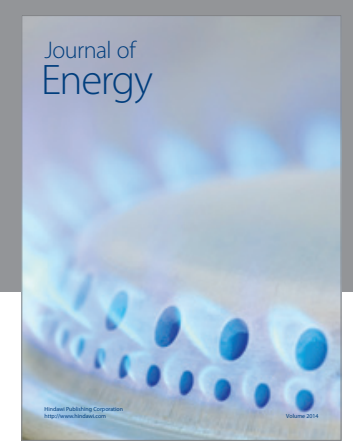

Journal of

Industrial Engineering
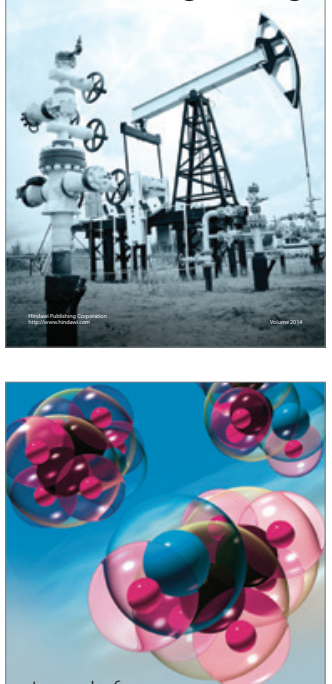

Fuels
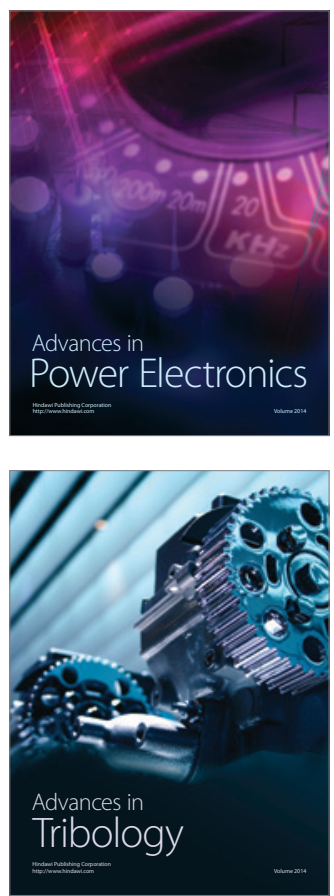

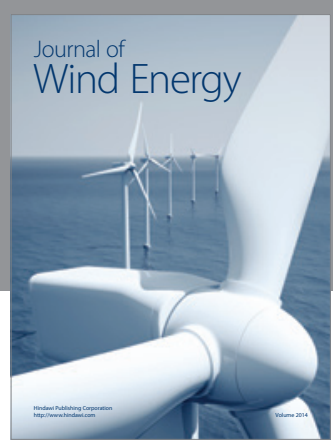

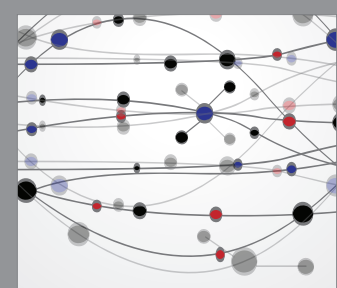

The Scientific World Journal

Submit your manuscripts at http://www.hindawi.com

Journal of

Structures
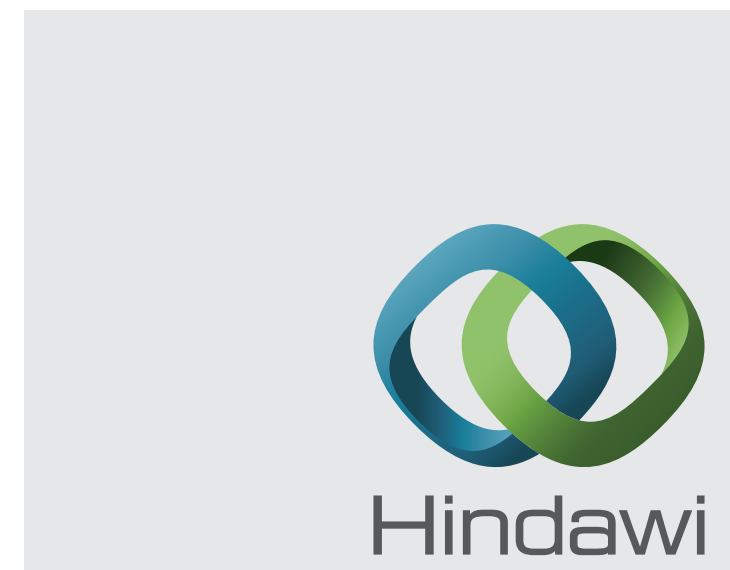

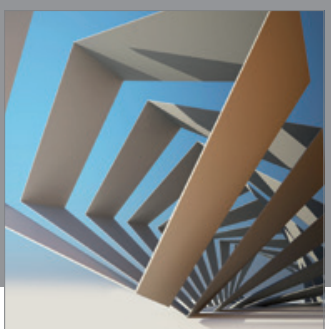

Rotating

Machinery
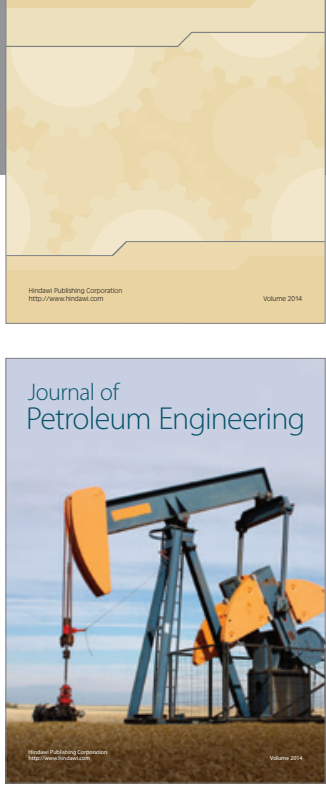

Journal of

Solar Energy
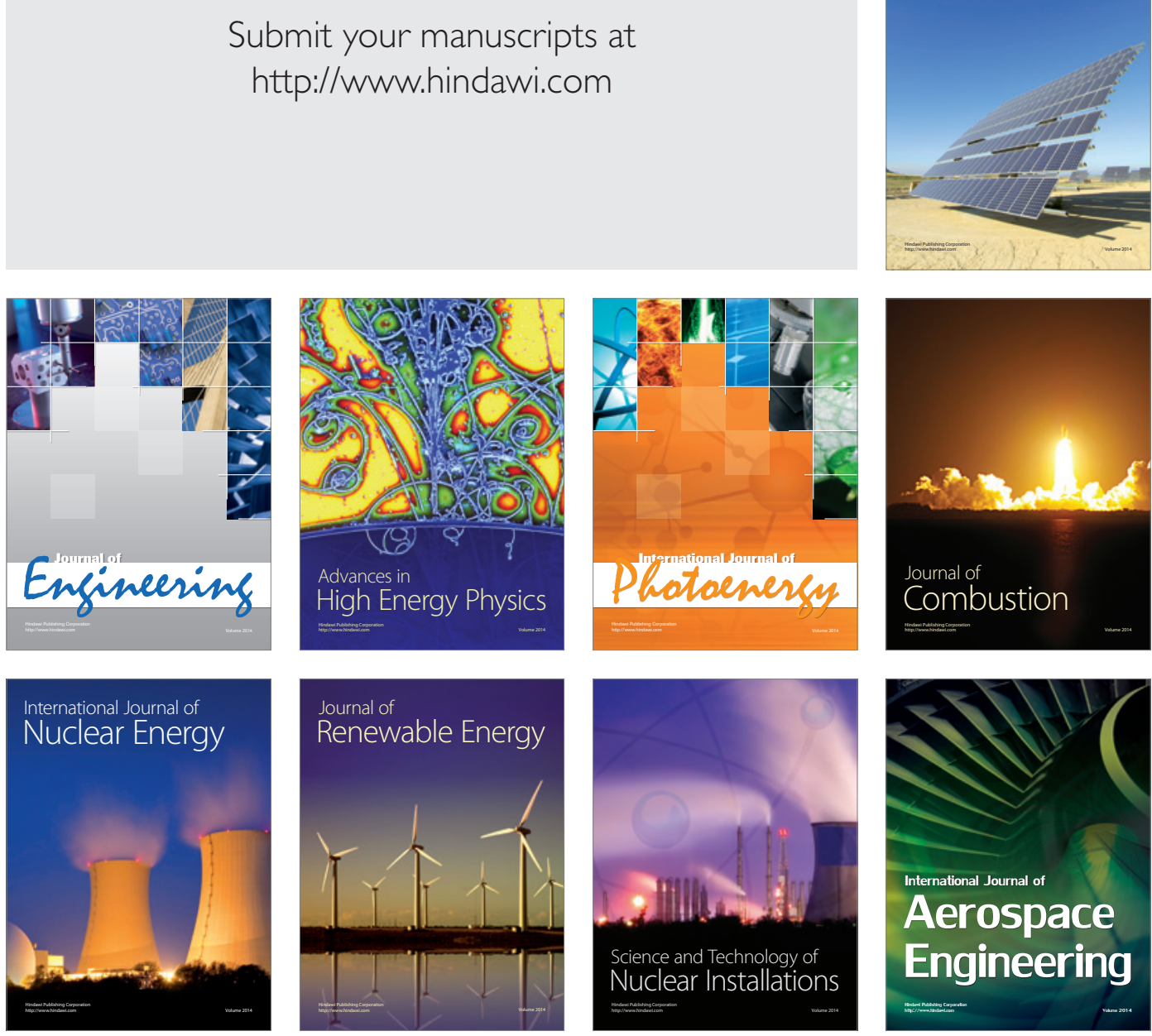